\title{
Early failure of the autograft valve after the Ross procedure
}

\author{
Tobias Walker, MD, ${ }^{a}$ Markus K. Heinemann, MD, ${ }^{a}$ Wilke Schneider, MD, ${ }^{a}$ Manfred Wehrmann, MD, ${ }^{b}$ \\ Burkhard Bültmann, MD, and Gerhard Ziemer, MD, ${ }^{\mathrm{a}}$ Tübingen, Germany
}

$\mathrm{T}$ he Ross procedure is an established method for replacement of the aortic valve, mainly for young patients who do not want any form of anticoagulation. The postoperative outcome of the patients is strongly affected by the limited indication for this procedure. Contraindications include connective tissue diseases like the Marfan syndrome. Only a few reports have been published concerning early failure of the autograft valve after the Ross procedure without obvious signs of connective tissue disease.

\section{Clinical Summary}

In September 1999 a Ross procedure was performed in a 22-yearold male patient with a combined aortic valve disease of presumably rheumatic etiology. The patient was the ideal age for the Ross procedure, and the pulmonary valve showed no aberrations in various examinations. The Ross procedure was performed by a subcoronary implantation technique without any intraoperative or postoperative problems.

The intraoperative situs showed a tricuspid aortic valve with mucoid degenerative alterations. In the histologic examination there was no hint of any infectious or sterile inflammation. A specimen of the ascending aorta showed no sign of any alteration.

The young man was discharged from the intensive care unit on the first postoperative day. Transthoracic echocardiography demonstrated good function of the neoaortic valve, no signs of paravalvular leakage, and a mild insufficiency of the mitral valve. The heart rate was a normal sinus rhythm at 74 beats/min. The patient was discharged home on the 11th postoperative day in good clinical condition.

Progressive dyspnea and increasing fatigue led to a renewed admittance to our hospital 3 months after the primary operation. The physical examination showed a slightly icteric patient. Auscultation of the heart revealed a grade $2 / 6$ systolic and a grade $3 / 6$ to $4 / 6$ diastolic murmur. The patient was in sinus rhythm with a heart rate of about 80 beats $/ \mathrm{min}$.

Laboratory findings included a decreased level of hemoglobin $(9.1 \mathrm{~g} / \mathrm{dL})$, an increased level of bilirubin $(2.2 \mathrm{mg} / \mathrm{dL})$, and a lactic

From the Department of Thoracic, Cardiac and Vascular Surgery a and Department of Pathology, ${ }^{b}$ Tübingen University Hospital, Tübingen, Germany.

Received for publication Nov 9, 2000; accepted for publication Nov 13, 2000.

Address for reprints: Prof Dr med G. Ziemer, University Hospital Tübingen, Department of Thoracic, Cardiac and Vascular Surgery, Hoppe- Seyler- Straße 3, 72076 Tübingen, Germany (E-mail: gdziemer@med.uni-tuebingen.de)

J Thorac Cardiovasc Surg 2001;122:187-8

Copyright ( 2001 by The American Association for Thoracic Surgery 0022-5223/2001 $\$ 35.00+0 \quad \mathbf{1 2 / 5 4 / 1 1 3 1 6 3}$

doi: $10.1067 / \mathrm{mtc} .2001 .113163$
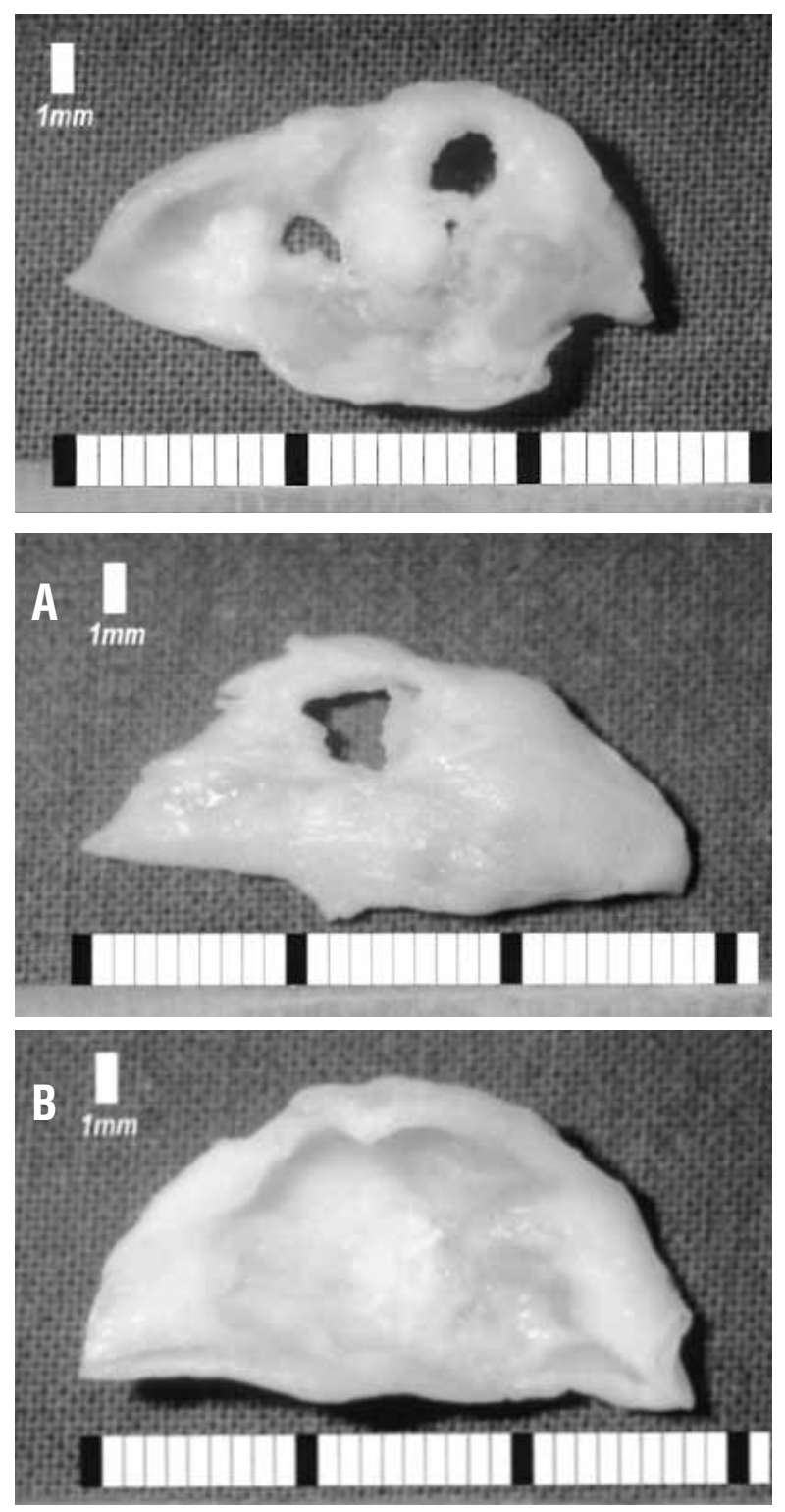

Figure 1. A, Excised right coronary cusp with two central perforations measuring up to $0.4 \mathrm{~cm}$ in diameter. $B$, Left coronary cusp with one central perforation measuring up to $0.5 \mathrm{~cm}$. C, Noncoronary cusp with no macroscopic or microscopic deficiency.

dehydrogenase of $1637 \mathrm{U} / \mathrm{L}$. The microscopic blood examination showed numerous fragmented erythrocytes. A transthoracic echocardiogram demonstrated severe insufficiency of the autograft valve without any signs of paravalvular leakage. Early failure of 
the autograft was therefore obvious, and the need for a replacement of the neoaortic valve was obvious.

The intraoperative situs showed an autograft with good diastolic closure of the cusps. The right coronary cusp, however, had two central perforations measuring up to $0.4 \mathrm{~cm}$ (Figure 1, $A$ ), and the left coronary cusp had one perforation measuring $0.5 \mathrm{~cm}$ in diameter (Figure 1,B). The noncoronary cusp had no deficiencies (Figure 1,C). These findings explained the massive insufficiency of the valve despite good diastolic closure. On the patient's request, we implanted a mechanical prosthesis after explantation of the autograft. The further intraoperative progress was without any complications.

Histologic examination of the explanted valve showed a severe mucocystic degeneration of the valvular stroma. The perforations resulted from these alterations; the intact cusp showed no signs of any alteration. Further examination showed no signs of an old or florid endocarditis.

\section{Comment}

After a primary uneventful Ross procedure, a rapidly progressive insufficiency of the neoaortic valve developed in a 24-year-old man. This insufficiency was not the result of a rapid dilatation of the pulmonary autograft, as described by Solymar, ${ }^{1}$ David, ${ }^{2}$ and their associates. The intraoperative situs showed three central perforations in two of the three cusps. Iatrogenic damage of the valve during the implantation was considered unlikely because of initial- ly good valve function. Histologic examination of the excised valve showed severe mucocystic degeneration of the stroma with the perforations of the cusps resulting most likely from these alterations. As described by de Sa and colleagues, ${ }^{3}$ cystic degeneration of the ascending aorta is more prevalent in patients with a bicuspid aortic valve. Our patient had a tricuspid aortic valve, so that we conclude that there must be other signs, too, which may indicate a defect in the valvular stroma.

Early and rapid degeneration of an autograft valve may result from previously unrecognized connective tissue disease in patients who have no other clinical signs of such disease. Identifying these predictive factors of an early valve degeneration must be the subject of further investigations to select the ideal patient for a Ross procedure.

\section{References}

1. Solymar L, Südow G, Holmgren D. Increase in size of the pulmonary autograft after the Ross operation in children: growth or dilatation? $J$ Thorac Cardiovasc Surg. 2000;119:4-9.

2. David TE, Omran A, Ivanov J, et al. Dilatation of the pulmonary autograft after the Ross procedure. J Thorac Cardiovasc Surg. 2000;119:210-7.

3. de Sa M, Moshkovitz Y, Butany J, David TE. Histologic abnormalities of the ascending aorta and pulmonary trunk in patients with bicuspid aortic valve disease: clinical relevance to the Ross procedure. J Thorac Cardiovasc Surg. 1999;118:588-94. 